\title{
Sport Integrity Opportunities in the Time of Coronavirus
}

\author{
Yannis Pitsiladis ${ }^{1,2}$ (D) Borja Muniz-Pardos ${ }^{3} \cdot$ Mike Miller $^{4} \cdot$ Michele Verroken $^{5}$
}

Published online: 2 July 2020

(c) Springer Nature Switzerland AG 2020

The coronavirus (COVID-19) pandemic provides a unique opportunity for reflection on integrity challenges facing sport. The imposed lockdown in response to this global crisis has resulted in most sporting events being postponed or cancelled including the 2020 Olympic Games. While this pandemic threatens to overwhelm an already fragile world sport, it provides an unprecedented opportunity for stakeholders in sport to learn vital lessons from COVID-19, to delve into unresolved integrity issues and develop creative and long-lasting solutions. This commentary focuses on two issues affecting the integrity of sport: doping and technological fairness.

Measures taken by governments to defeat COVID-19 such as policing of social distancing rules through applications monitoring people's behaviour, self-testing at home, and collaborations amongst rival companies to speed up the development of a vaccine and search for treatments can all help inform sport. The goal to flatten the curve of a pandemic to safeguard public health involves all athletes, regardless of sport or rivalry and is a welcome departure from the disproportionate focus on health protection of 'individual' athlete/team [1]. Many technologies that enable us to work from home such as teaching students on-line, applications for medical advice, prescriptions and referrals, and treating patients in hospitals/care homes via video links are destined to alter the way we live and work after the pandemic and can be used to enhance sport integrity.

Yannis Pitsiladis

y.pitsiladis@brighton.ac.uk

1 Collaborating Centre of Sports Medicine, University of Brighton, Eastbourne, UK

2 International Federation of Sports Medicine (FIMS), Lausanne, Switzerland

3 GENUD (Growth, Exercise, Nutrition and Development) Research Group, University of Zaragoza, Zaragoza, Spain

4 World Olympians Association, Lausanne, Switzerland

5 Sporting Integrity Ltd, Stoke Mandeville, UK
Anti-doping testing in sport has all but ceased due to the lockdown raising suspicion about doping opportunities. Creative thinking such as in-home self-drug testing by the U.S. Anti-Doping Agency involving athletes who consented to provide urine and small dried blood samples at home is controversial [2]. Athletes are required to complete their normal whereabouts, while a doping control officer connects via videoconference during a prescribed time period. Using testing kits sent to their homes, athletes provide their urine samples in the bathroom whilst their laptop remains outside the room, after giving the doping control officer a virtual tour. Sample provision is timed and the athlete measures their urine temperature to demonstrate it is freshly provided. Athletes also apply an auto-sampler to their arm and collect a blood sample, and are responsible for packaging and sending their samples to the anti-doping laboratory.

This evolution in anti-doping could further advance testing. The pledge by the International Olympic Committee (IOC) of $\$ 10$ million for new anti-doping approaches with particular focus on 'omics' technologies, Dried Blood Spots, and an ambitious long-term storage and reanalysis programme [3], could provide some fresh thinking into athlete profiling and testing. It may be more effective to combine such innovations with technology that allows for remote testing and other approaches such as artificial intelligence to determine the optimal time and athlete to test, and to ensure more frequent testing as well as the integrity of the sample collection with real time assessment. These developments will undoubtedly generate new challenges such as big data management, data protection, data security and other complex issues [4]. However, the cost-benefit opportunity to reduce the cost of sample collection, increase frequency of testing and convenience to athletes will help to improve trust in the anti-doping system.

There is also the issue of 'technological fairness', as seen in the sport of athletics [5] over the past four years with the launch of carbon fibre plate (CFP) shoes. Since their introduction, all world records in the half- and full-marathon have been broken raising concerns that this technology leads to a distinct non-physiological advantage [5]. The improvement 
in performance by athletes running in CFP shoes is similar to some blood doping substances included on the Prohibited List of the World Anti-Doping Agency (WADA), such as erythropoietin, which can improve performance by approximately 5\% [6]. World Athletics reacted by announcing new rules stating that sole thickness of a shoe must not exceed $40 \mathrm{~mm}$ and the shoe must be on sale for at least four months before use in competition [7]. These rules have resulted in a 'footwear arms race' to develop patented CFP inserts by shoe companies. Postponement of the Tokyo Olympics gives World Athletics the opportunity to commission an independent review focusing on 'technological fairness' to evaluate the impact of technology on physical performance and therefore on the integrity of sporting competition. Accordingly, recent developments in wearable technology could be used to provide a standard method to assess this impact both in training and competition [8]. How this matter is resolved will have wider implications for all sport. Pressures are already mounting about expiration of doping sanctions, secret training sessions and doping regimes free from testing.

This pause in the business of sport due to COVID-19 provides time and opportunity to consider new approaches to address ongoing integrity challenges. Positive action extends beyond the realm of sports integrity with far reaching benefits for the field of sport and exercise medicine. Let us take advantage of this opportunity.

\section{Compliance with Ethical Standards}

Funding The authors did not receive any specific grants for this research from any funding agency in the public, commercial or notfor-profit sectors.

Conflict of interest The authors have no competing interests to declare.

\section{References}

1. Mann RH, Clift BC, Boykoff J, Bekker S. Athletes as community; athletes in community: covid-19, sporting mega-events and athlete health protection. Br J Sports Med. 2020. https://doi.org/10.1136/ bjsports-2020-102433.

2. Futterman M. Doping tests go virtual. Is it temporary or a glimpse of the future?-The New York Times [Internet]. 2020. https:// www.nytimes.com/2020/04/15/sports/olympics/coronavirus-drugtesting.html. Accessed 21 Apr 2020.

3. International Olympic Committee. IOC President announces USD 10 million "action plan" and calls for tougher sanctions against "entourage" members to strengthen protection of clean athletes Olympic News [Internet]. 2019. https://www.olympic.org/news/ ioc-president-announces-usd-10-million-action-plan-and-calls -for-tougher-sanctions-against-entourage-members-to-strengthen -protection-of-clean-athletes. Accessed 21 Apr 2020.

4. Tanisawa K, Wang G, Seto J, Verdouka I, Twycross-Lewis R, Karanikolou A, et al. Sport and exercise genomics: the FIMS 2019 consensus statement update. Br J Sports Med. 2020. https://doi. org/10.1136/bjsports-2019-101532

5. Muniz-Pardos B, Sutehall S, Angeloudis K, Guppy FM, Bosch A, Pitsiladis Y. Commentaries on viewpoint: physiology and fast marathons: recent improvements in marathon times are not physiological. J Appl Physiol. 2020;128:1081.

6. Haile DW, Durussel J, Mekonen W, Ongaro N, Anjila E, Mooses M, et al. Effects of EPO on blood parameters and running performance in Kenyan athletes. Med Sci Sport Exerc. 2019;51:299-307.

7. World Athletics. World Athletics modifies rules governing competition shoes for elite athletes [Internet]. https://www.worldathle tics.org/news/press-release/modified-rules-shoes. Accessed 17 Feb 2020.

8. Muniz-Pardos B, Sutehall S, Gellaerts J, Falbriard M, Mariani B, Bosch A, et al. Integration of wearable sensors into the evaluation of running economy and foot mechanics in elite runners. Curr Sport Med Rep. 2018;17:480-8. 